\title{
Exploring Student's Representation Process in Solving Ill-Structured Problems Geometry
}

\begin{tabular}{|c|c|}
\hline \multicolumn{2}{|c|}{$\begin{array}{l}\text { Lydia Lia PRAYITNO }{ }^{1} \text {, Purwanto PURWANTO }{ }^{2 *} \text {, Subanji SUBANJI }{ }^{3} \text {, } \\
\text { Susiswo SUSISWO }{ }^{4} \text {, Abdur Rahman AS'ARI } \\
\text { Mathematics Education Department, Universitas Negeri Malang, Malang, Indonesia } \\
{ }^{1} \text { ORCID: 0000-0002-5416-8787, }{ }^{5} \text { ORCID: 0000-0003-0974-4068, }{ }^{3} \text { ORCID: 0000-0002-4281- } \\
\text { 1923, }{ }^{4} \text { ORCID: 0000-0001-6461-6283, }{ }^{5} \text { ORCID: 0000-0002-4959-0043 }\end{array}$} \\
\hline Article history & This study is to reveal the construction process of student representation \\
\hline $\begin{array}{l}\text { Received: } \\
28.02 .2020\end{array}$ & $\begin{array}{l}\text { in solving of ill-structured geometry problems. The three phases } \\
\text { involved in the construction process are interpreting the problem, giving }\end{array}$ \\
\hline $\begin{array}{l}\text { Received in revised form: } \\
01.05 .2020\end{array}$ & $\begin{array}{l}\text { opinions, and concluding. A total of four high school students } \\
\text { participated in Surabaya and Sidoarjo in this qualitative study. They used } \\
\text { visual and symbolic representations to solve the ill-structured problems. }\end{array}$ \\
\hline $\begin{array}{l}\text { Accepted: } \\
04.05 .2020\end{array}$ & $\begin{array}{l}\text { The research data were obtained from the sheets of ill-structured } \\
\text { geometry problems (ISGP), video recordings, and interviews. The data }\end{array}$ \\
\hline Key words: & analysis through three stages, data identification, data presentation, and \\
\hline $\begin{array}{l}\text { Construction, } \\
\text { deductive, inductive, } \\
\text { visual, } \\
\text { symbolic }\end{array}$ & $\begin{array}{l}\text { conclusion. } \\
\text { constructing the visual and symbolic representations was carried out by } \\
\text { the students when interpreting the problem. The subjects provide data to } \\
\text { support problem-solving process, such as initial length and width. The } \\
\text { construction process through the visual representation began with the } \\
\text { process of giving meaning. They drew rectangle with a length and width. } \\
\text { Likewise, when giving an opinion, they referred to the drawings they } \\
\text { made with length and width of different sizes. They used symbolic } \\
\text { representation as a length and width for the initial situation in the process } \\
\text { of giving meaning. Through the use of variables, they could perform } \\
\text { calculations so as to determine the proposals used as a solution. Two } \\
\text { patterns that the students did during the process of the representation } \\
\text { construction, are deductive and inductive. It is important for teachers to } \\
\text { know the process of representation of students when solving ill- } \\
\text { structured problems. It needs to be enlarged and in line with the criteria } \\
\text { to obtain the general description of the representation of the construction } \\
\text { process when solving the problem. Then, teachers should design } \\
\text { meaningful learning so they can connect concepts that their students can } \\
\text { use to solve problems. }\end{array}$ \\
\hline
\end{tabular}

\section{Introduction}

In Indonesia, one of the objectives of school mathematics learning is problem-solving. This is stated in the National Council of Teachers of Mathematics (NCTM, 2000) which emphasizes that problem-solving should not be separated because it is is an integral part of the learning process. It aims to make students actively involved in practicing their mathematical

\footnotetext{
* Correspondence: purwanto.fmipa@um.ac.id, Phone: +628125235230
} 
knowledge and skills in the problem-solving process. Many problems related to everyday life situation implicate ill-structured problems (Hong, 1998; Jonassen, 1997). Jonassen (1997) explains that an ill-structured problem situation implicate one or two aspects which are not specifically explained to the problem where the problem is not clearly described even the information provided is also incomplete. To solve ill-structured problems, problem solvers are given the freedom to determine various processes and solutions in accordance with their perceptions (Hong, 1998).

Students who are taught to solve ill-structured problems means that students have been provided with useful problem-solving skills in their daily lives (Hong, 1998). This skill does not only require them to detect certain solutions to solve that problems, but also the justifications and arguments that exist in the problem-solving process. Thus, it is possible that there will be many solutions found, many paths to find solutions, even though no single solutions is found (Jonassen, 2003). In addition, the skill of solving ill-structured problems can evaluate mathematical skills that have been mastered, train creative thinking, motivate, and assist the students in learning new situations that they do not yet know (Erdoğan, 2020; Ulusoy \& Argun, 2019).

One classification of mathematical problems is geometry. Solving ill-structured problems will involve geometry in which students are required to be skilled in arithmetic problem-solving and own good conceptual and procedural knowledge about geometry concepts (Ulusoy \& Argun, 2019; Wong, et al., 2007). In other words, understanding ill-structured geometry problems requires a lot of knowledge, including philology, geometry, and schematic knowledge (Wong et al., 2007). In this section, representation leads an important part in understanding the construction of problems (Swastika, et al., 2020) involving the students' geometry concepts. Some researchers support the above-mentioned opinion, especially related to geometrical problems verbally presented. Usually problem solvers represent verbal problems in geometry problem situations using visual representations or symbol representations (Anwar, et al., 2016). Visual representations include pictures, diagrams or graphs, while symbolic representations consist of numbers, operating signs and connections, algebraic symbols.

Representation is one of the standard processes that students must master besides problem solving (NCTM, 2000). The use of representation, allows the students to express abstract mathematical ideas to be more concrete and facilitate them in reflecting. Representation has a key part in the problem-solving process, particularly, in solving ill-structured problems (Anwar \& Rahmawati, 2017; Bal, 2014; Hwang, et al., 2007; Swastika et al., 2020). The role of representation as a tool to explore and comprehend the problem situation presented (Stylianou, 2010; Stylianou \& Silver, 2004) as well as the problem solving process. Representation can also be used as a means to monitor and evaluate the problem solving process. When the students solve the same problem, they do not rule out the possibility of using different representations. This is because the representation used by the students in the problem-solving process is influenced by their learning experiences (Anwar \& Rahmawati, 2017)

The results of some research on representation in problem solving (Anwar \& Rahmawati, 2017; Anwar et al., 2016; Boonen et al., 2016; Santia, et al., 2019; Ulusoy \& Argun, 2019) shows that representation is effective in problem solving. Anwar \& Rahmawati (2017) conducted a qualitative study involving four $8^{\text {th }}$ grade students to describe the construction process of students' symbolic and verbal representations when solving problems based on Polya's stages. The results of this study indicate that the process of constructing symbolic representations was used by students since understanding the problem for variables whose values are unknown. This is to help and facilitate the students in the problem solving process. While the process of 
constructing verbal representations begins by writing down all information known using its own language. From here the students plan and present the written counting process.

Research by Anwar, et al. (2016) is a case study to describe the mathematical representation of $7^{\text {th }}$ grade students in building relational understanding of the concepts of area and circumference of rectangles. Two students were selected as subjects based on their mathematical representation characteristics. The results of this study indicate that there are two ways in which the students build relationships between the concepts of circumference and area of a rectangle using visual and symbolic representations.

Boonen et al. (2016) studied eight elementary school teachers to examine the use of visual representations to solve non-routine problems. The teachers are given short training so that they can produce representations during teaching. The results of this study indicate the use of teacher representation is based on personal preference compared to conformity with the given word problem characteristics. Santia (2019) conducted a qualitative study involving two subjects to explore the use of mathematical representations in solving ill-structured problems involving quadratic functions. The results show that verbal and symbolic representations are used by the subjects to calculate, detect, correct mistakes, and justify their answers. However, visual representation is only used by the first subject to detect and correct errors. Ulusoy \& Argun (2019) examined three high school students to investigate changes in representation in solving word geometry problems using different clinical interviews. The results of this study indicate that the students translate verbal representations into pictorial without reading carefully so as to produce incorrect representations. Through interviews the students are given the opportunity to change their representation by carefully reading the problem, verifying, monitoring the solution, and realizing their mistakes.

From some of the studies above, research is a representation process involving algebra (Anwar \& Rahmawati, 2017), Geometry (Anwar et al., 2016; Ulusoy \& Argun, 2019), and quadratic functions (Santia et al., 2019). If viewed from the type of problem, the word problem (Anwar \& Rahmawati, 2017; Boonen et al., 2016; Ulusoy \& Argun, 2019) and ill-structured problems (Anwar et al., 2016; Santia et al., 2019). This study involves geometrical problems about the perimeter and area of a rectangle by using ill-structured problems. The difference between this research and Anwar's (2016) research lies in the form of the problem. Anwar's research deals with determining the length and width of the rectangle if the area is known. While this study, the subjects asked to propose changes in length and width so that the area is maximally increased and the circumference is less than or equal to the initial perimeter. So, this study focuses on the process of representation construction in solving ill-structured geometry problems.

Ill-structured problems are one type of problems based on everyday life where the situation is not concrete, the problem is not clearly defined, and has the openness presented in complex situations (Hong \& Kim, 2016). Generally, ill-structured problems are raised in specific material contexts and complex situations. The existence of a problem that is not clearly defined and it requires problem solvers to understand, search for, select information relevant to the problem (Hong \& Kim, 2016) and also bring up supporting information (Abdillah, et al., 2016).

The implication of solving ill-structured problems is that the problem solvers can use many methods to find solutions, right answers that are not single, and involve a variety of knowledge and representations (Jonassen, 1997; Niederhauser, Ogilvie, \& Toy, 2013; Santia, et al., 2019). For this reason, the problem solver must be able to identify and justify the answer from various perspectives under his beliefs. This is where the role of structural and conceptual knowledge deeply supports the process of solving ill-structured problems. 
The four stages of solving ill-structured problems are the representation of problems, developing solutions, developing justification, monitoring, and evaluation (Ge \& Land, 2003; Jonassen, 1997). Students solving ill-structured problems will carry out these stages by paying attention to situations in everyday life to develop solving strategies that will be used. Additionally, the students are asked to organize information on the problem to bring up additional information that supports the justification process. Thus, the direction of thinking is demanded by a new understanding of the problem, monitoring and evaluating various alternative methods to produce the right solution.

Another opinion on problem solving is stated by Bakry \& Bakar (2015) that it consists of three stages, namely (1) interpretation of the problem, (2) giving opinions, and (3) concluding. In this study, the researchers adapted these stages to solve ill-structured problems according to the stages of Ge \& Land (2003) and Jonassen (1997). The stage of solving problems from Bakry and Bakar was chosen because the stages used were more specific so as to produce solutions to the problems being solved. The three stages of the representation construction process solve the ill-structured problems described in the table 1 below.

Table 1. Stages of the representation process (Bakry \& Bakar, 2015)

\begin{tabular}{ll}
\hline Stages & Description \\
\hline Interpreting the problem & $\begin{array}{l}\text { Interpreting the problem by using their own language } \\
\text { Bringing up ideas for solving the problem } \\
\text { (Problems representation) }\end{array}$ \\
\hline \multirow{2}{*}{ Giving opinion } & $\begin{array}{l}\text { Proposing opinion along with the evidence and computation (Developing } \\
\text { solutions and justification) } \\
\text { Analyzing the proposed opinion (monitoring and evaluation) }\end{array}$ \\
\hline Concluding & Giving the final solution of the problem \\
\hline
\end{tabular}

\section{Method}

\section{Research Design}

This is a qualitative study, researchers generally chooses participants based on research objectives but in this study the researcher selected the students who voluntarily participated in data collection activities. The goal is that students do not object to the process of data collection so that the data obtained is more accurate. From the responses of the students collected, the researcher grouped them based on the representations used, namely visual and symbolic representations. Then, from each representation one subject was chosen to provides a true solution and one subject that does not find a solution. The subject of this study consisted of 4 students.

\section{Participant}

Participants in this study were students of grade X and XI in public and private high schools in Surabaya and Sidoarjo. Both schools are equally accredited "A" and located in two different cities. Demographic of participants in this study is summarized in Table 2.

Table 2. Demographic Structures of participant

\begin{tabular}{lll}
\hline Class & Aspects & N \\
\hline \multirow{3}{*}{ Schools } & Public high schools 10 $10^{\text {th }}$ grade & 18 \\
& Public high schools 11 & 13 \\
& Private high schools $10^{\text {th }}$ grade & 21 \\
& Private high schools 11 $11^{\text {th }}$ grade & 17 \\
\hline
\end{tabular}




\begin{tabular}{lll}
\hline \multirow{2}{*}{ Gender } & Male & 23 \\
& Female & 46 \\
\hline \multirow{3}{*}{ Age } & $15-16$ years & 18 \\
& $16-17$ years & 49 \\
\hline \multirow{2}{*}{ Departement } & $\geq 18$ years & 2 \\
\hline \multirow{2}{*}{ Culture } & Sains & 41 \\
& Social & 28 \\
\hline & Javanese & 59 \\
& Maduranese & 8 \\
\hline
\end{tabular}

\section{Data Collection}

The research data were obtained from sheets of ill-structured geometry problems (ISGP), video recordings, and interviews. Before given a target problem, the students were trained to think aloud in solving algebra problems. Then, the students were given 40 minutes to solve ISGP and the problems used in this study include

"You are asked to submit two proposed changes in the length and width of a rectangle (in percentage form) so that the area increases maximally but the perimeter is less than or the same as the perimeter of the initial rectangle. According to your proposal earlier, which one gives the maximum area according to the conditions above? Explain your answer!"

Video recordings were used to document the results of think aloud conducted by the students. The focus of this research lies in the representation construction process carried out by the students in solving ISGP. The results were combined with the results of student work which were then classified based on the representations used by students, namely visual representations and symbolic representations. Next, four people were chosen to be interviewed with criteria that for each representation one subject was chosen that provided the correct solution and one subject that did not find a solution. Subjects were chosen based on the representations used and considerations of mathematics teachers that is students with good verbal communication. Semi-structured interviews were conducted to clarify the parts of the representation construction process that the subjects went through in solving ill-structured problems about geometry. The semi-structured interview guide contains key questions that are open for the researcher to develop as needed (Creswell, 2012). Key questions in this study are shown in Table 3

Table 3. Key Questions in Semi-structured Interview

\begin{tabular}{|c|c|c|}
\hline Stages & Description & Key Question \\
\hline $\begin{array}{l}\text { Interpreting the } \\
\text { problem }\end{array}$ & $\begin{array}{l}\text { - Interpreting the problem by using their own } \\
\text { language } \\
\text { - Bringing up ideas for solving the problem } \\
\text { (Problems representation) }\end{array}$ & $\begin{array}{l}\text { - What is the meaning of the problem? } \\
\text { - What ideas do you have to solve the } \\
\text { problem? } \\
\text { - Why you used the idea? }\end{array}$ \\
\hline Giving opinion & $\begin{array}{l}\text { - Proposing opinion along with the evidence } \\
\text { and computation (Developing solutions and } \\
\text { justification) } \\
\text { - Analyzing the proposed opinion (monitoring } \\
\text { and evaluation) }\end{array}$ & $\begin{array}{l}\text { - How about the proposed changes? } \\
\text { - Why did you proposed it? } \\
\text { - What was your analysis of your } \\
\text { proposal? }\end{array}$ \\
\hline Concluding & Giving the final solution of the problem & - Why did you choose it as a solution? \\
\hline
\end{tabular}




\section{Data Analysis}

Data analysis was carried out through three stages, i.e (1) data identification, (2) data presentation, and (3) conclusion drawing (Miles, Huberman, \& Saldana, 2014). As a beginning of the data analysis, the researcher carefully copied the results of students' think aloud and examined the results of student work to get a general understanding of the data based on the stages of solving structured problems that are complemented by the results of the interview. In examining the process, a representation was produced where specifically the researcher also examined the following matters (1) how the students read the problem to understand the reading that produces the representation; (2) whether the students master the concept of flat figure and understand the role of conceptual knowledge when producing representations; and (3) how the students monitor solutions. Presentation of data in this study is a set of information that has been arranged that allows drawing conclusions and actions. The next stage carried out was analytical activities which included conclusions and verification.

\section{Findings}

Research data in the form of visual representations and symbolic representations were made by the students during solving geometric ill-structured problems consist of four subject. The four subjects are shown in Table 4.

Table 4. Research subjects

\begin{tabular}{lll}
\hline Representation & Subject with solution & Subject without solution \\
\hline Visual & MA & RA \\
Simbolik & TA & NI \\
\hline
\end{tabular}

Referring to the data that has been collected, it is need to provide a special code between visual or symbolic representation. Visual representation is indicated by application of images in solving geometry problems, while symbolic representations are indicated by application of mathematical symbols in solving geometry problems. The following describes the process of constructing student representations.

\section{Finding 1. The Process of Construction of Visual Representation in Solving ISGP Description of $M A$}

\section{a-Interpreting the problem}

MA reading ISGP and providing the meaning by constructing a visual representation that is drawing a rectangle presented in Figure 1. To support their understanding, MA gave out initial length and width a rectangle then determine the initial area and perimeter.

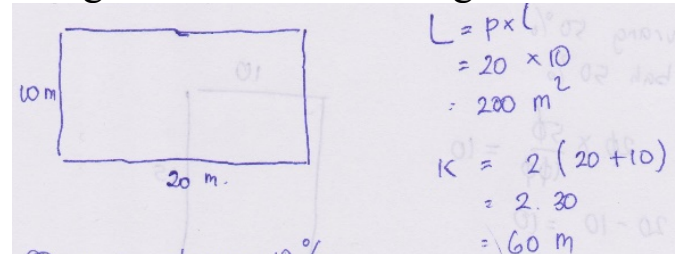

$\begin{aligned} \text { Area } & =\text { length } \mathrm{x} \text { width } \\ & =20 \times 10 \\ & =200 \mathrm{~m}^{2} \\ \text { Perimeter } & =2(20+10) \\ & =2.30 \\ & =60 \mathrm{~m}\end{aligned}$

Figure 1. MA interpreting the problem

Researcher (P) clarify it through interview.

$P \quad:$ About what you did earlier? 
MA : Asked proposal change length and width of rectangel, the area increasing maximal but the perimeter should not be more initial.

$P \quad$ : What do you think first?

$M A \quad:$ Drawing rectangle mam

$P \quad:$ Why?

MA : Easy for me to understand so I don't imagine it

$P \quad:$ What do you think to solve this?

MA : Ehm..easy for me if the initial length and width are there mam so I have key area and perimeter

\section{b-Giving Opinion}

MA proposed three proposed changes in length and width in terms of percentages, (1) the length less $10 \%$ and width plus $25 \%$; (2) length plus $25 \%$ and width less $10 \%$; and (3) length less $25 \%$ and width plus $50 \%$. From each of the proposals, MA did the translation and computation to produce a new length and width. Then the MA drew the rectangle (visual representation), determined the length and width, area and perimeter then analyzed it. A suitable proposal is made as a solution and MA's progress work presented in Table 5.

Table 5. Progress work's MA

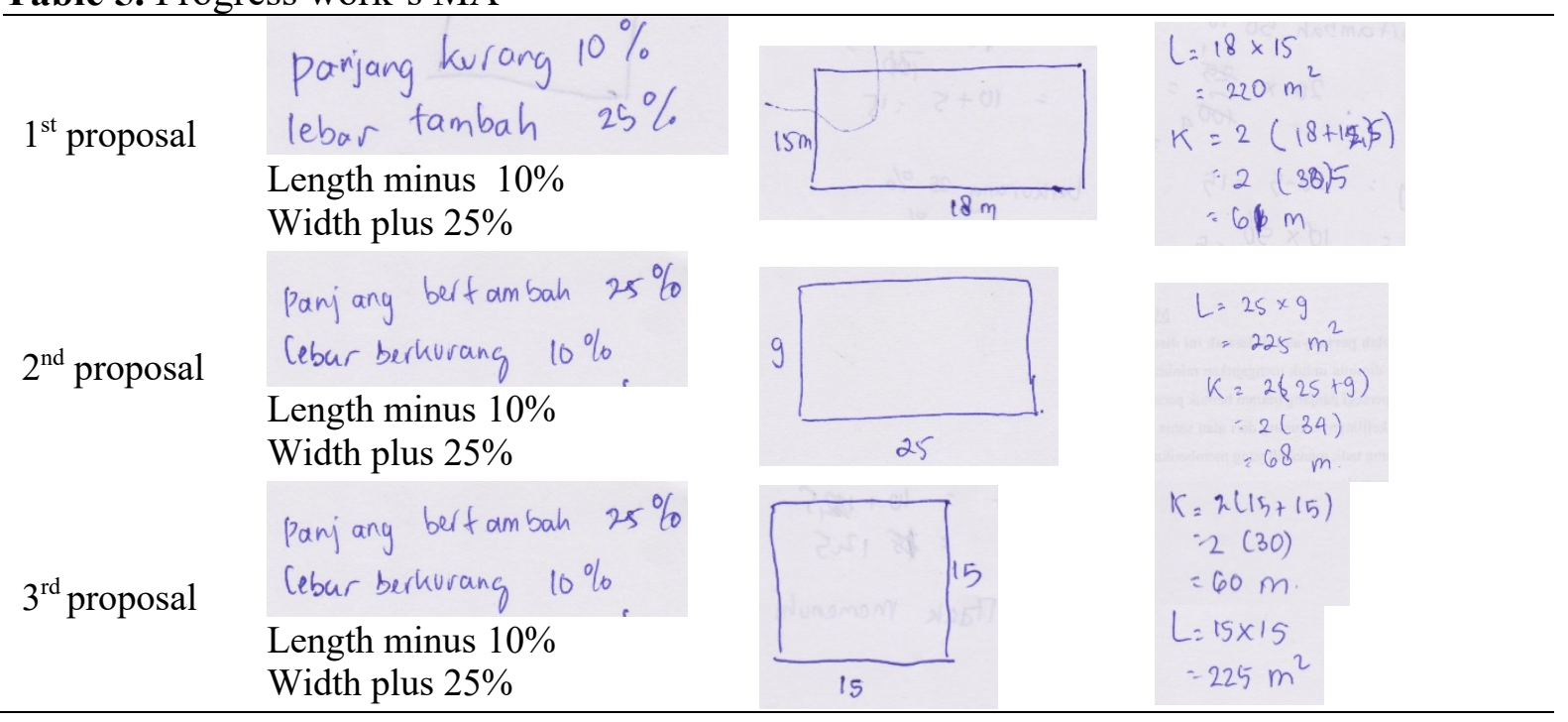

AM analyzes each proposal submitted, the first and second proposals do not match, while the third proposal suits the criteria determined by the problem. To clarify MA's work progress researcher take on interview.

$P \quad:$ How about your proposals?

MA : I have 3 proposals mam, first length less $10 \%$ and width plus 25\%; second length plus $25 \%$ and width minus $10 \%$; and third length minus $25 \%$ and width plus $50 \%$

$P \quad$ : How do you think about that proposal?

MA : I just assumed then calculated the length and width. After that determine the area and perimeter. If the perimeter suitable the requirements, the proposal is a solution

$P \quad:$ what if it doesn't suitable?

MA : That's not a solution mam 


\section{c-Concluding}

After analyzing the proposal then MA gave the final answer which was a solution, which was length minus $25 \%$ and width plus $50 \%$. Researcher (P) clarifies it through interview.
$P \quad$ : From your proposal which is the solution?
MA : I think, my third proposal mam
$P \quad:$ Why do you choose the third proposal?
MA : My first and second proposals are not suitable mam, the perimeter more than 60 meters
$P \quad$ : Are you sure?
$M A \quad$ : Sure mam

From the results of the video recording, MA's work, and interview above it can reveal the visual representation process of the MA in solving the ISGP. The visual representation process by MA is presented in Figure 2.

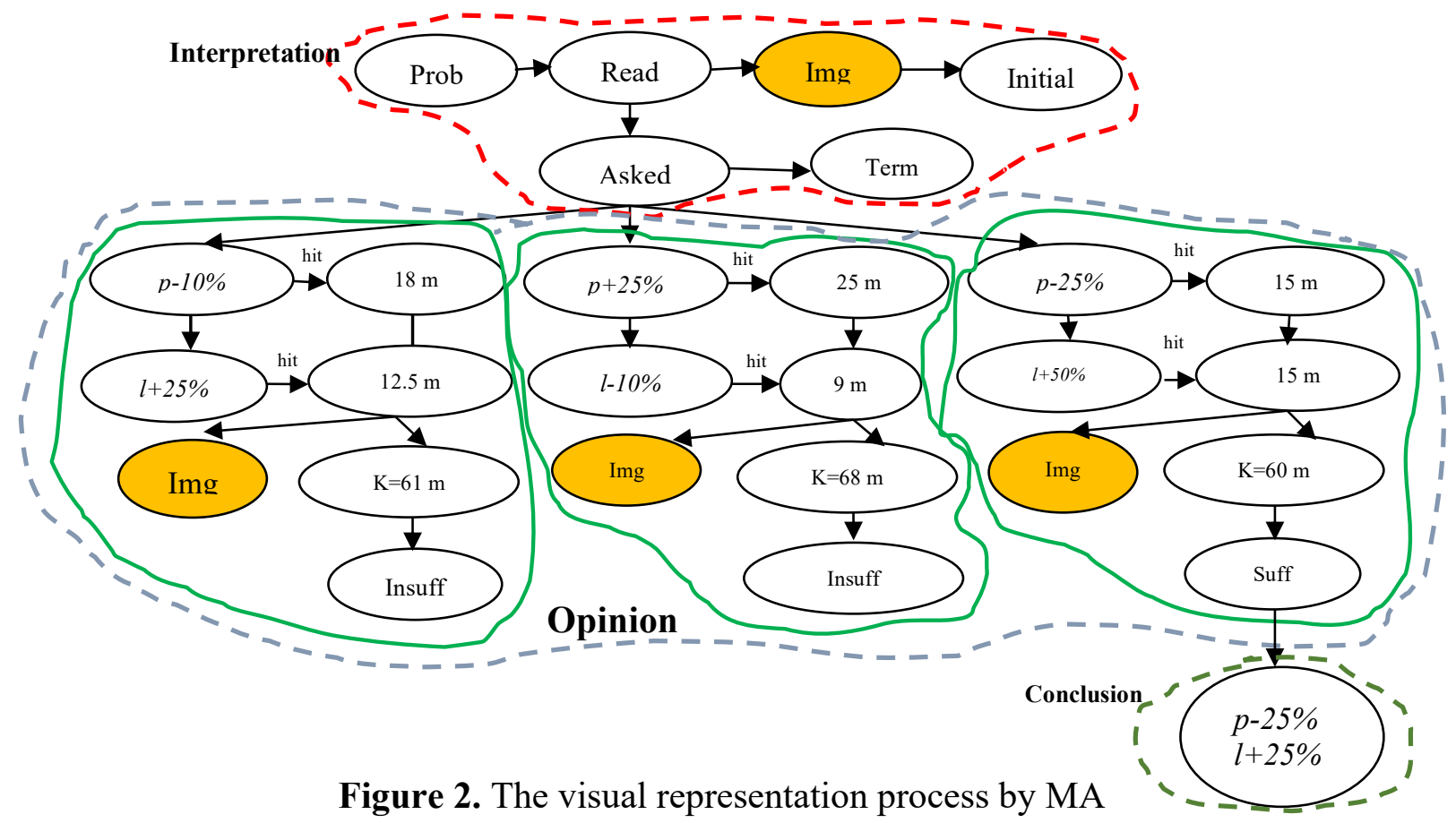

Description:

Asked Proposed change of length and $p-25 \%$ Length minus $25 \%$ width in percentage

Term Term perimeter $(\mathrm{K}) \leq 60 \mathrm{~m}$ and $l+50 \% \quad$ Width plus $50 \%$

area $(\mathrm{L})>200 \mathrm{~m}^{2}$

$1+25 \% \quad$ Width plus $25 \%$

$p+25 \% \quad$ Length plus $25 \%$

Insuff Not eligible

$l-10 \% \quad$ Width minus $10 \%$

Suff Eligible

Hit Translation and counting 


\section{Description of $R A$}

\section{a-Interpreting the problem}

RA started reading the problem and underlined a keywords on the problem sheet. The results of RA's work presented in Figure 3.

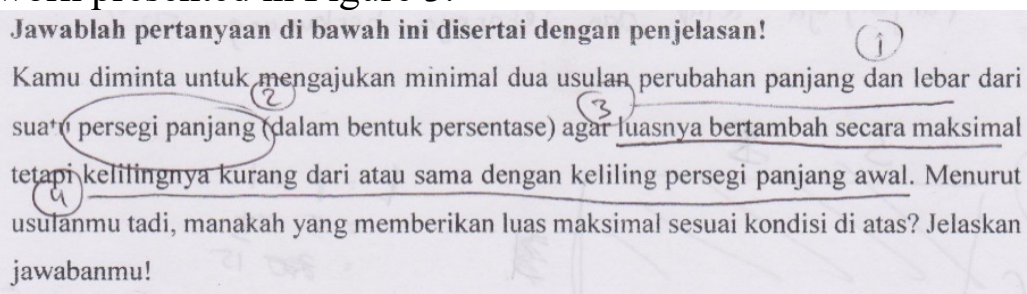

Figure 3. RA underlined a keywords on the problem sheet

From the figure 3, RA assigned four keywords (1) change length and width; (2) rectangle; (3) area increasing maximal; and (4) perimeter less than or equal to initial. Then RA constructed a visual representation that is rectangle image with the initial length and width. Arrangement initial length and width to support understanding and justification was then assigned to what was asked of the problem. Visual representation of RA interpreting problems that is drawing a rectangle presented in Figure 4.

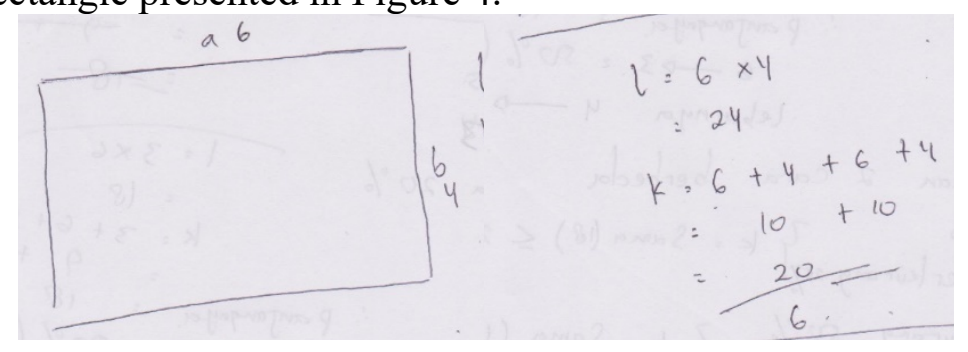

$$
\begin{aligned}
\text { Area } & =6 \times 4 \\
& =24
\end{aligned}
$$

Parameter $=6+4+6+4$

$=10+10$

$=20$

Figure 4. RA Interpreting the problem

To explore RA's interpretation of the problems, the researcher clarified it through interview.

$P \quad:$ What the problem was about?

$R A \quad:$ This is a rectangle, asked to determine changes in length and width but requirements the area increasing maximal and the perimeter should not be more 20.

$P \quad:$ What do you think first?

$R A \quad:$ Drawing rectangle length $=6$ and width $=4$

$P \quad:$ Why?

$R A \quad:$ I don't imagine it mam [laughing]

$P \quad:$ Okey, why you underlined this problem sheet

$R A \quad:$ Oh, I think that a keyword to solve this problem that is change length and width; rectangle; area increasing maximal; and perimeter less than or equal to initial.

$P \quad:$ What do you think to solve this?

$R A \quad:$ I have length $=6$, width $=4$ so area $=24$ and the perimeter $=20$

\section{b-Giving Opinion}

RA began by describing a rectangle and continued by proposing two proposed changes in length and width. RA conducted a trial and error to determine the appropriate length and 
width, so that two proposals were decided, (1) new length $=6$ and new width $=3$; and (2) new length $=3$ and new width $=6$. Based on the proposal, the RA calculated the percentage of the proposed length and width changes. Both proposals were then analyzed by RA, RA's progress work presented in Table 6 .

Table 6. Progress work of $R A$

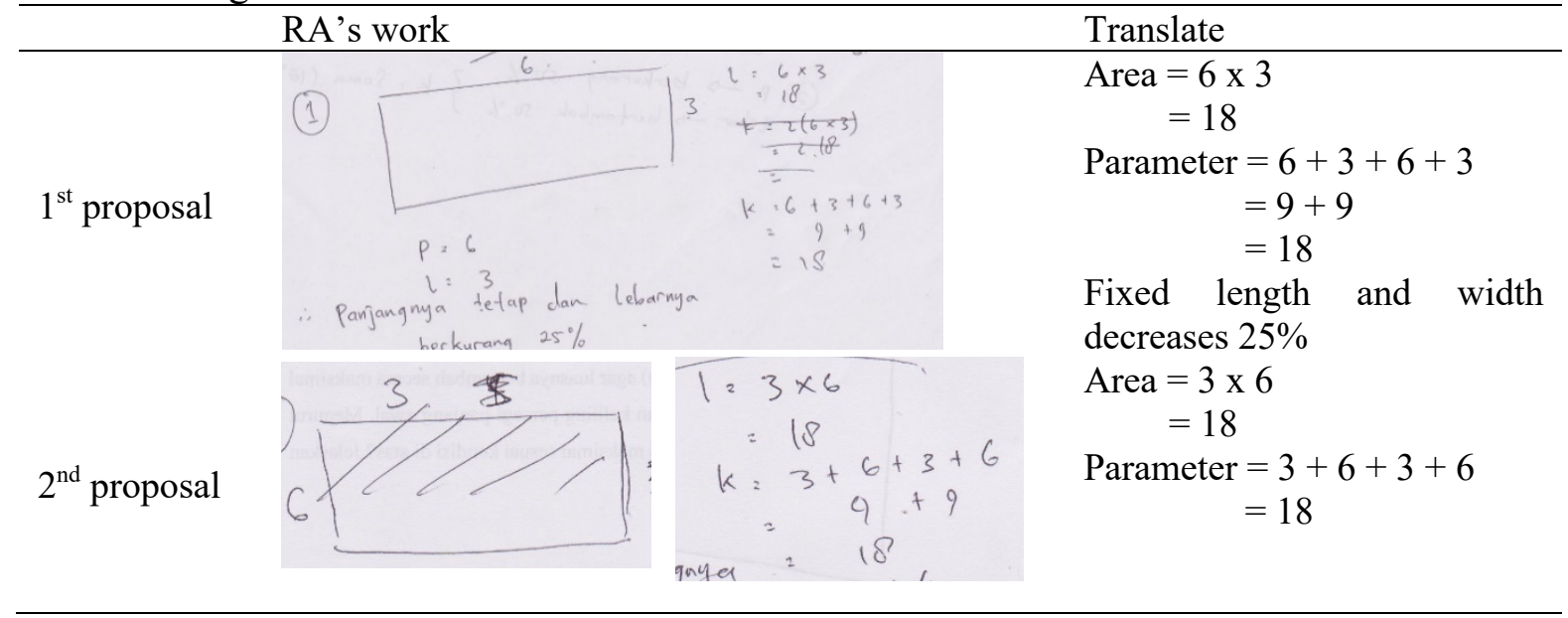

RA's proposals do not suit the criteria determined by the problem and to clarify RA's work progress the researcher takes on interview.

$P \quad$ : How about your proposals?

RA : I have two proposals mam. The first, length=6 and width=3; the second, I turned it over so length $=3$ and width $=3$

$P \quad:$ How do you think about that proposal?

$R A \quad:$ I just trial and error mam because I choose easy number to get percentage.

$P \quad$ : Any proposal suitable?

$R A \quad:$ No solution mam

\section{c-Concluding}

Because the proposal did not meet the requirements, RA decided that there was no solution that met. Researcher (P) clarify it through interview.

$P \quad:$ Why you don't have solution?

RA : I'm confused about how to keep that condition

$P \quad:$ Why?

RA :I don't know mam

From the results of the video recording, RA's work, and interview above can describe the visual representation process by RA is presented in Figure 5. 


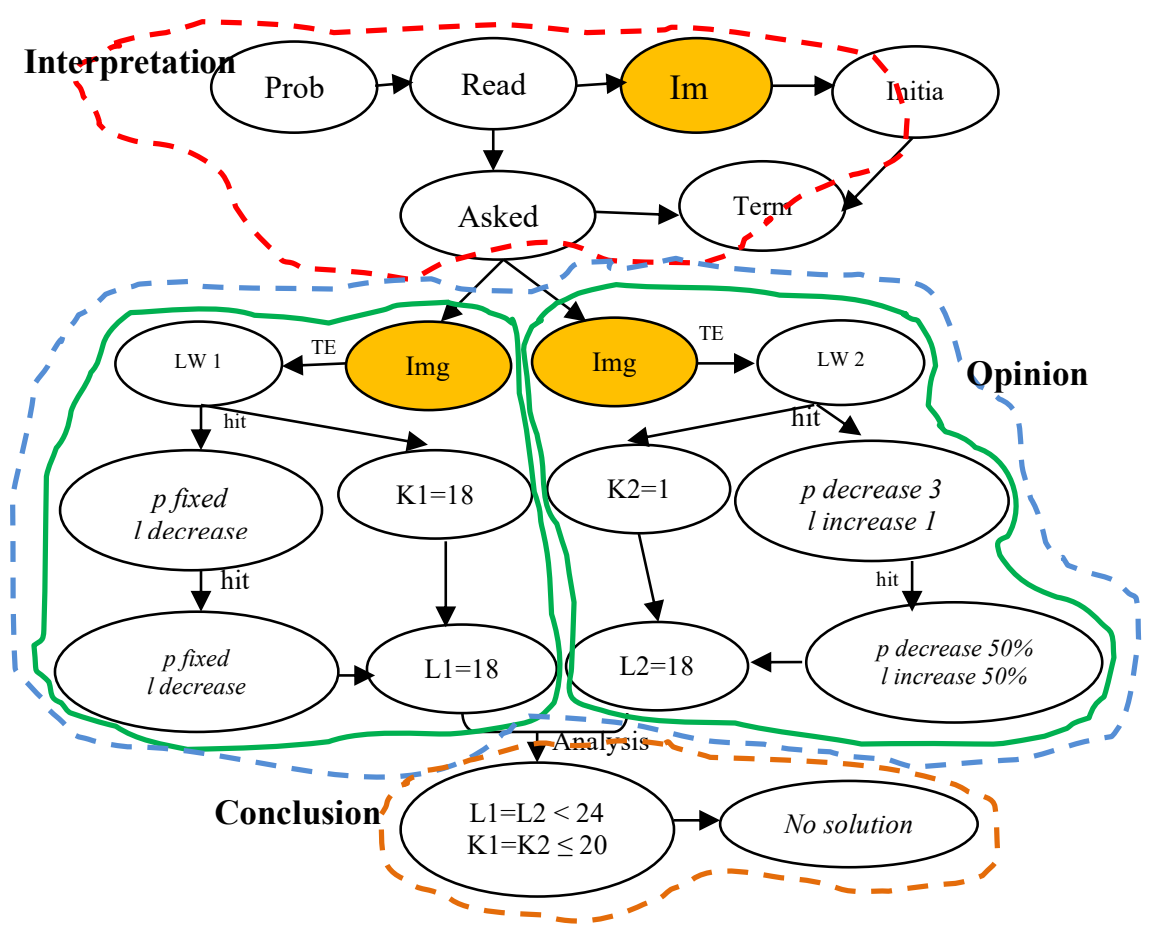

Figure 5. The visual representation by RA

Description:

Prob

Read

Img

Initial

Asked

Term

LW 1

LW 2

TE

Hit
Problem

Read the problem

Depicting rectangle

Initial length (6), initial width (4), initial perimeter, and initial area

Proposed change of length and width (\%)

Term perimeter $(\mathrm{K}) \leq 20$ and area $(\mathrm{L})>24$

$1^{\text {st }}$ proposal, new length $=6$, new width $=3$

$2^{\text {nd }}$ proposal, new length $=3$, new width $=6$

Trial and Error

Translation and counting process

Finding 2. The Process of Symbolic Representation Construction in Solving ISGP Description of $T A$

a-Interpreting the problem

TA started reading problems and construction symbolic representation of the problem. Then, TA determined what was asked by relating the terms to the problem. TA supposed that the length is equal to two times $(p=2 l)$ the width so that the area is $2 l^{2}$ and the parameter is $6 l$. TA's work presented in Figure 6.

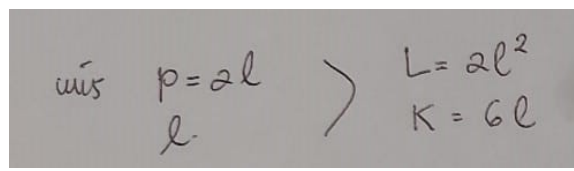

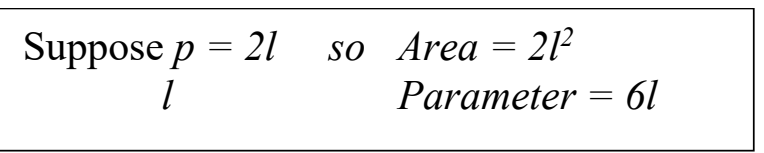

Figure 6. TA's interpretation 
When relating to the problem situation, TA tried to associate with prior knowledge about the square. TA explained that the maximum area of a rectangle could be obtained from the area of a square, so TA had the concept of making a rectangle as a square. This is supported clarify researcher $(\mathrm{P})$ through interview.
$P \quad$ : What are you solving about?
TA :It's about maximum area of a rectangle but the perimeter should not be more than initial
$P \quad$ : How do you think to solve it?
TA : Ehm...suppose length is twice the width
$P \quad:$ Then?
TA : Maximum area can be achieved if the length equals the width. So, the rectangle transformed into square mam

\section{b-Giving Opinion}

TA proposed that the length was equal to the width, then the length decreased by $25 \%$ and the width increased by $50 \%$, followed by the translating and computation process. Then, TA determined the new perimeter $(K=6 l)$ and the new area of the rectangle $\left(\mathrm{L}=2,5 l^{2}\right)$. From the opinion given, TA decided that changing the length and width of the rectangle so that the area increases maximally but the perimeter is fixed by making the length decrease by $25 \%$ and the width increases by $50 \%$ In solving problems, TA only gave one proposal because TA believed in the answers given. TA's work presented in Figure 7.

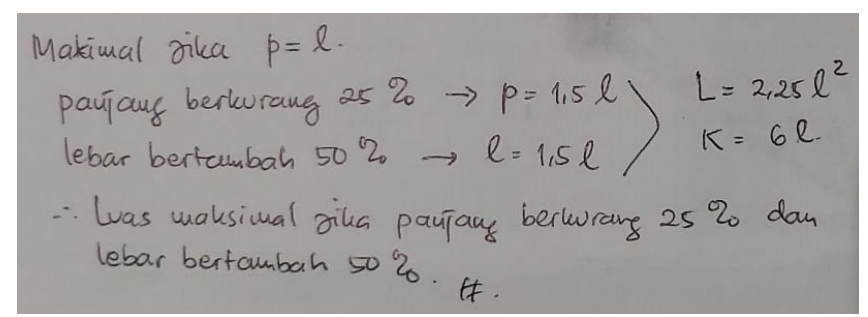

Translate:

Area maximal if length $=$ width

Length decreased $25 \% \rightarrow p=1,5 l$

Width increased $50 \% \rightarrow l=1,5 l$

So, Area $=2,25 l^{2}$ and

Parameter $=6 l$

Area maximal if length decreased

$25 \%$ and width increased $50 \%$

Figure 7. TA's Giving Opinion

The researcher $(\mathrm{P})$ clarify it through interview.

$P \quad$ : How about your proposals?

MA $\quad:$ Just one mam, length decreased $25 \%$ and width increased $50 \%$

$P \quad:$ Why are you sure?

MA : as I explained earlier that it's transformed to square that the length equals the width. So, it's the solution

\section{c-Concluding}

The conclusion given by TA is area maximal if length decreased by $25 \%$ and width increased $50 \%$. From the results of the video recording, TA's work, and interview above can be described the symbolic representation process is presented in Figure 8. 


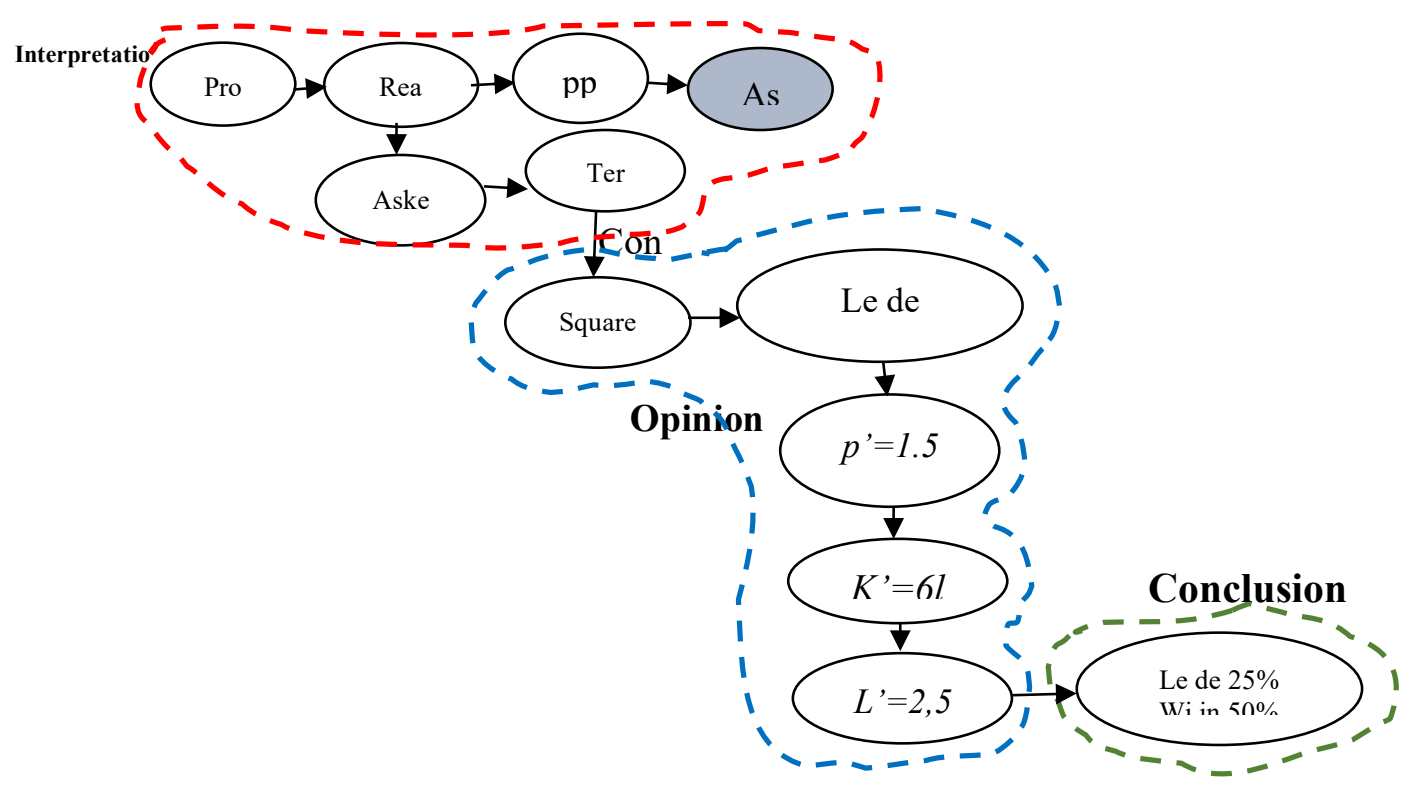

Figure 8. The simbolic representation process by TA

Description:

$\begin{array}{ll}\text { Prob } & \text { Problem } \\ \text { Read } & \text { Read the problem } \\ \text { PP } & \text { Rectangle }\end{array}$

Asm Assume $p=2 l$

Asked Proposed change of length and width (\%)

Term $\quad$ Term $\mathrm{K}^{\prime} \leq \mathrm{K}$ and area $(\mathrm{L})>2 l^{2}$

Con Connect problems with previous experiences

Le de $25 \% \quad$ Reduced length $25 \%$

Wi in 50\% Increased width $50 \%$

\section{Description of the NI}

\section{a-Interpreting the problem}

NI started reading the problem then constructing the symbolic representation was begun. NI gave the initial conditions of the rectangle, namely $p_{0}=8 \mathrm{~cm}$ and $l_{\mathrm{o}}=5 \mathrm{~cm}$ to support their understanding. NI revealed what was asked of the problem by paying attention to the given conditions and related it to the initial conditions that is area $=40 \mathrm{~cm}^{2}$ and the parameter $=26$ $\mathrm{cm}$. NI's work presented in Figure 9.

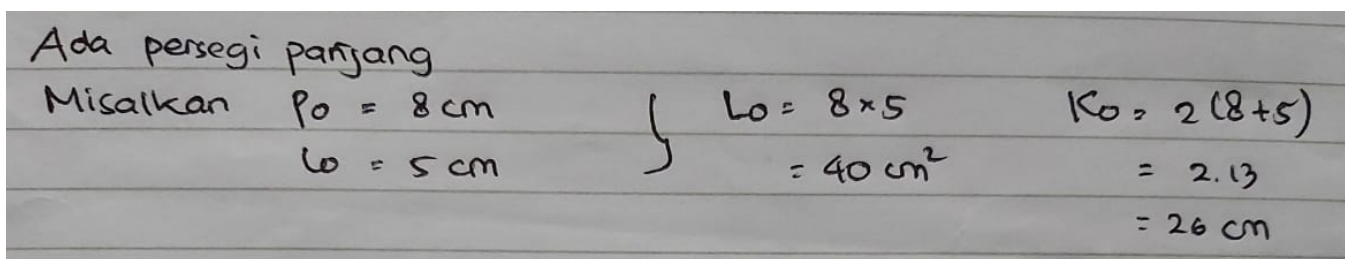




$$
\begin{aligned}
& \text { Translate } \\
& \text { A rectangle } \\
& \text { Suppose } \mathrm{p}_{\mathrm{o}}=8 \mathrm{~cm} \quad \text { Lo }=8 \times 5 \quad \text { Ko }=2(8+5) \\
& 1_{0}=5 \mathrm{~cm} \quad=40 \mathrm{~cm}^{2} \quad=2.13 \\
& =26 \mathrm{~cm}
\end{aligned}
$$

Figure 9. NI Interpretation the problem

Researcher $(\mathrm{P})$ clarify it through interview.

$P \quad:$ : About what you did earlier?

NI : Hhm ... proposal changes length and width of rectangle, the area increasing maximal but the perimeter should not be more $26 \mathrm{~cm}$.

$P \quad:$ What do you think?

NI : We must initial condition as a focus to solve this problem

$P \quad:$ What are you doing?

$\mathrm{NI} \quad:$ I suppose initial length $=8 \mathrm{~cm}$ and initial width $=5 \mathrm{~cm}$ mam

$P \quad:$ Why you choose that number?

NI : I like it [smiling]

$P \quad:$ Are you sure to solve it?

NI : I'll try

\section{b-Giving Opinion}

NI provided two proposed changes in length in the form of percentages, namely (1) length increases by $20 \%$ and (2) width increases by $20 \%$. From the results of the interview it was revealed that the proposal given by NI based on trial and error. From this proposal, NI conducted a translation and computation process to get a new length and a new width. After that, NI then determined the new perimeter and new area of the rectangle. NI was carried out analysis process by comparing the new perimeter with the initial perimeter of the rectangle, so that NI revealed that the new perimeter was greater than 26 and did not match the conditions specified. NI's work in giving opinion presented in Figure 10.

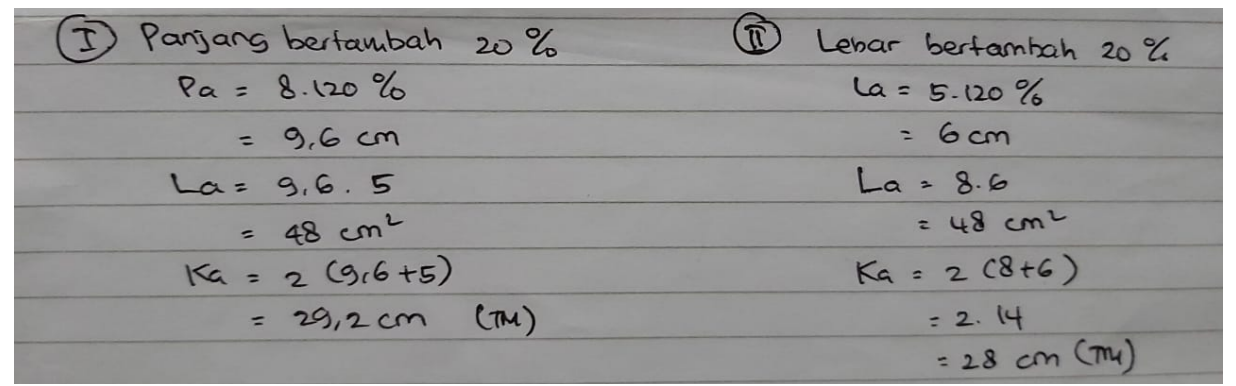

$$
\begin{array}{cc}
\text { I. Length increased } 20 \% & \text { II. Width increased } 20 \% \\
\mathrm{P}_{\mathrm{a}}=8.120 \% & 1_{\mathrm{a}}=5.120 \% \\
=9,6 \mathrm{~cm} & =6 \mathrm{~cm} \\
\mathrm{La}=9,6.5 & \mathrm{La}=8.6 \\
=48 \mathrm{~cm}^{2} & =48 \mathrm{~cm}^{2} \\
\mathrm{Ka}=2(9,6+5) & \mathrm{Ka}=2(8+6) \\
=29,2 \mathrm{~cm} \text { (Insufficient) } & =2.14=28 \mathrm{~cm} \text { (Insufficient) }
\end{array}
$$

Figure 10. NI Giving the opinion 
Researcher $(\mathrm{P})$ clarify it through interview.

$P \quad$ : How about your proposals?

NI : I have two proposals, first length increased by $20 \%$ and the second width increased $20 \%$

$P \quad:$ How do you think about that proposal?

NI : [Laughing] no one comply with the condition because all perimeter is more than 26

$P \quad:$ What if it doesn't match?

NI : I don't have a solution mam

\section{c-Concluding}

NI concluded that there was no solution to the problem and explain the mistake of choosing a proposal change. Researcher (P) clarifies it through interview.

$P \quad:$ Why you don't have a solution?

NI : I think I made a mistake in submitting a proposal mam. I'm confused about what to do with it, so I submit it like it

From the results of the video recording, NI's work, and interview above can describe the symbolic representation process is presented in Figure 11.

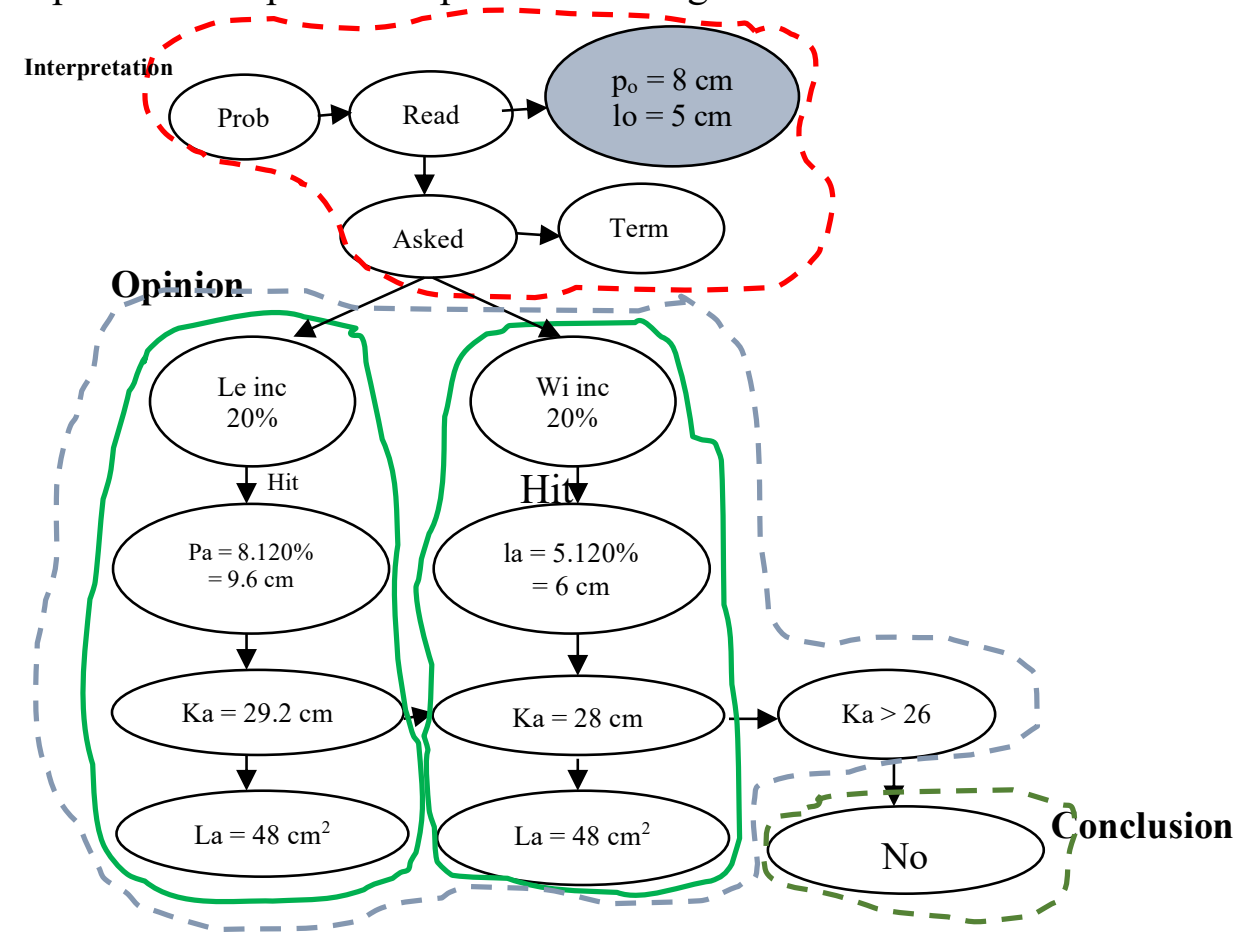

Figure 11. The simbolic representation process by NI

Description:

Prob

Read

Problem

Asked

Read the problem

Term

Proposed change of length and width (\%)

Le inc $20 \%$

Term: Ka $\leq$ Ko and area (L) $>40$

Wi inc 20\%

Increased length $20 \%$

Hit Increased width $20 \%$

Translation and counting process 


\section{Discussion}

The aims of this study was to describe the process of constructing the student representations in solving ill-structured geometry problems. The thinking process is a process that involves receiving information internally and externally, involving the storage and retraction of information stored in long-term memory. So in this study, the thought process referred to is (a) giving meaning to the problem, carried out through gathering information, storing it, expressing it through representation; (b) making an opinion, carried out by proposing changes in length and width, doing translation and providing proof of computation; and (c) making conclusion, through the final solution provided. From the results of the work done by the subjects and their description above, the four subjects revealed the meaning of the problem presented through representation, namely visual and symbolic representation. Students who are able to express the meaning of a problem demonstrate their ability to evaluate problem situations (Erdoğan, 2020) that are the key to successful problem solving.

This is because new knowledge can be built by giving meaning to problems that are realized through understanding the situation of the problem (Cooper \& Alibali, 2012; Hegarty, Mayer, \& Monk, 1995; Özsoy, Kuruyer, \& Çakiroglu, 2015; Pape, 2004). The meaning of the problem understood by students is closely related to the knowledge and experience they have (Debrenti, 2015; Gagatsis \& Shiakalli, 2004; Xin, Jitendra, \& Buchman, 2005). Like the first finding, it shows that a rectangular image is a form of visual representation created by the subject to give meaning to the problem. Subjects describe a rectangle by giving an initial measure of length and width.

Meanwhile, the second finding shows that the subject uses symbolic representation to give meaning to the problem given. Symbolic representation skills are characterized by the skill of interpretating mathematical problems into arithmetic formula representations (Gagatsis \& Shiakalli, 2004; Goldin, 2002; Lesh, Post, \& Behr, 1987; Supandi, et. al, 2018). This symbol is well applied by the subjects in problem-solving process because its use simplifies the problemsolving process. The findings of this study are supported by Schoenfeld's theory (Stylianou, 2010) which states that representation as a means of understanding information from the problem situation presented. The representation used by students is certainly influenced by the knowledge and experience of the problem solver. The breadth of knowledge and the depth of experience possessed are the basis for determining the right problem solving strategy (Clement, 2008; Hegarty et al., 1995). Like the subjects NI, MA and RA, they have less mastery of rectangular knowledge because they only focus on rectangles. Meanwhile, TA has a good mastery of knowledge because it is able to associate with another flat figure concept, which is square. Linking concepts, rules, and principles is an important component in finding solutions when solving ill-structured problems (Hong, 1998; Jonassen, 1997; Shin et al., 2003).

There are two ways in which the subject submits a proposal, namely (1) determining the percentage change in length and width (deductive); and (2) determining the length and width then determining the percentage (inductive). In solving ill-structured problems it is not important to start from a particular point, because problem solvers are given the freedom to start (Jonassen, 1997; Shin et al., 2003). Students are free to express their opinions and associate the knowledge they have to solve the problem given. Each subject gave rise to an idea by adding information to help solve the problem as in the research Abdillah, et al. (2016) i.e. gives initial length and width. In this case, one important component when solving problems is computational ability (Karaahmetoğlu \& Korkmaz, 2019; Korkmaz \& Bai, 2019). This component is related to the conclusions the subject takes when the problem solving process is carried out. 
In providing conclusions, the subject must be able to make the right decision so that the desired final answer can be obtained. Students are required to express their opinions, make judgments, and maintain their belief in the final answers given (Jonassen, 1997; Shin et al., 2003). As was done by TA where TA only gives one proposal because TA believes the answers given are correct. Problem solving trains students to get used to having their own way of thinking, possessing perseverance, curiosity and self-confidence and having new experiences in situations they have just known (Pape, 2004).

There are two subject criteria that are not able to find the right solution, namely subjects who only surrender when they do not find solutions and subjects who try to propose all three to get solutions. Subjects who surrender when not finding a solution are included in the quitter criteria according to the theory of Adversity Quotient (Stoltz, 2000). MA conducts trial and error to find the final solution that suits the problem situation. The anxiety experienced by the MA did not make MA despair but kept MA trying to get a solution. The MA meets the criteria of students in the climber category according to the Aversity Quotient theory (Stoltz, 2000).

In solving ill-structured problems above, the four subjects have planned, monitored, and evaluated. These three activities are a series of skills in Metacognition (Woolfolk, 2009; Muhali, Yuanita, \& Ibrahim, 2019). Plan each subject by designing the strategy to use, start troubleshooting, identify the required information, order done, define keywords, and so on. Monitor performed subjects by realizing how the subject works determines the solution. Then, proceed with evaluating the results by giving the final answer, either as appropriate or not.

In instilling knowledge that can be utilized in the problem-solving process, the teacher has the role to instill knowledge in students through descriptive explanations, explanations giving reasons, and interpretive explanations (Murtafiah, et al., 2018). This is because mathematical knowledge involves facts, concepts, principles, operations, and procedures where each object requires a different way to be instilled in students. Meaningful learning has an important role to embed mathematical knowledge for that learning process should shift from centered on the teacher to student-centered (Sailin \& Mahmor, 2018). While, the treatment of errors made in mathematical problem-solving requires attention. Errors will seriously affect the future understanding of their mathematical concepts (Subanji \& Nusantara, 2016) so that students have a complete understanding of the concept.

\section{Conclusion}

Based on the results of this study, it can be concluded that in solving ill-structured problems, the students are required to identify information on problems well. To help solve problems the students can add information that supports the process of solving ill-structured problems. The process of constructing visual representations by the students begins when they find the meaning of the problem. The students give meaning to the problem through images that are equipped with the initial length and width. Likewise in building opinions, the students still focus on the picture even though in a different way up to the analysis stage. After the analysis is done, the students conclude a solution that fits the given problem. While the process of constructing symbolic representations is also carried out by the students when giving meaning to a problem that is as a substitute for length and width. In building opinions, students also use different methods up to the analysis stage. The use of variables makes it easy for students to do the computations so they can determine whether the proposed proposal can be used as a solution or not.

In constructing opinions, there are two ways students do, those are (1) determine the percentage 
change in length and width (deductive) and (2) determine the length and width then determine the percentage (inductive). Both of these ways do not guarantee the right solution in line with the situation of the problem. The limitation of this research is that there were only four students chosen based on the representation used and the final solution given. Therefore, it needs to be enlarged and in line with the criteria to obtain the general description of the representation of the construction process when solving the problem. One important thing needed to be mastered by the students is having the intelligence in solving difficult problem especially in problem solving. Thus, it needs further research which involves the intelligence of solving the problem when solving ill-structured problems. Besides that, in the learning process in the classroom teachers should design meaningful learning so they can connect concepts that their students can use to solve problems. Other researchers can discuss the pros and cons of the results of this study, so that knowledge about problem- solving can develop.

\section{Acknowledgement}

This study was supported by LPDP Kemenkeu, grant number 20161141081903. During the process of writing this paper, we thanks to Promotor, Co-Promotor, students who participated in this study.

\section{References}

Abdillah, Nusantara, T., Subanji, Susanto, H., \& Abadyo. (2016). The Students Decision Making in Solving Discount Problem. International Education Studies, 9(7), 57-63. https://doi.org/10.5539/ies.v9n7p57

Anwar, R. B., \& Rahmawati, D. (2017). Symbolic and Verbal Representation Process of Student in Solving Mathematics Problem Based Polya's Stages. International Education Studies, 10(10), 20-28. https://doi.org/10.5539/ies.v10n10p20

Anwar, R. B., Yuwono, I., As'ari, A. R., Sisworo, \& Rahmawati, D. (2016). Mathematical Representation by Students in Building Relational Understanding on Concepts of Area and Primeter of Rectangle. Educational Research and Reviewsv, 11(21), 2002-2008. https://doi.org/10.5897/ERR2016.2813

Bakry, \& Bakar, N. Bin. (2015). The Process of Thinking among Junior High School Students in Solving HOTS Question. International Journal of Evaluation and Research in Education, 4(3), 138-145.

Bal, A. P. (2014). The Examination of Representations used by Classroom Teacher Candidates in Solving Mathematical Problems. Educational Sciences: Theory \& Practice, 14(6), 2349-2365. https://doi.org/10.12738/estp.2014.6.2189

Boonen, A. J. H., Reed, H. C., Schoonenboom, J., \& Jolles, J. (2016). It's Not a Math Lesson We're Learning to Draw! Teachers' Use of Visual Representations in Instructing Word Problem Solving in Sixth Grade of Elementary School. Frontline Learning Research, 4(5), 55-82. https://doi.org/http://dx.doi.org/10.14786/flr.v4i5.245

Clement, J. J. (2008). Does Decoding Increase Word Problem Solving Skills ? University of Nebraska-Lincoln. Retrieved

http://digitalcommons.unl.edu/mathmidactionresearch

Cooper, J. L., \& Alibali, M. W. (2012). Visual Representations in Mathematical ProblemSolving: Effects of Diagrams and Illustrations. In Proceedings of the 34th Annual Meeting of The North American Chapter of the International Group for the Psychology of Mathematics Education (pp. 281-288). Kalamazoo: Western Michigan University.

Creswell, J. C. (2012). Educational Research, Planning, Conducting, and Evaluating Quantitative and Qualitative Research (4th ed.). Boston: Pearson. 
Debrenti, E. (2015). Visual Representations in Mathematics Teaching: An Experiment with Students. Acta Didactica Napocensia, 8(1), 19-26. Retrieved from eric.ed.gov

Erdoğan, F. (2020). The Relationship Between Prospective Middle School Mathematics Teachers' Critical Thinking Skills and Reflective Thinking Skills. Participatory Educational Research (PER), 7(1), 220-241.

Gagatsis, A., \& Shiakalli, M. (2004). Ability to translate from one representation of the concept of function to another and mathematical problem solving. Educational Psychology, 24(5), 645-657. https://doi.org/10.1080/0144341042000262953

Ge, X., \& Land, S. (2003). Scaffolding students' problem solving processes in an ill-structured task using question prompts and peer interactions. Educational Technology Research and Development, 51(1), 21-38. Retrieved from http://dx.doi.org/10.1007/BF02504515

Goldin, G. . (2002). Representation in Mathematical Learning and Problem Solving. In Handbook of International Research In Mathematics Education (pp. 197-218). New Jersey: Lawrence Erlbaum Associates Publishers.

Hegarty, M., Mayer, R. E., \& Monk, C. A. (1995). Comprehension of Arithmetic Word Problems : A Comparison of Successful and Unsuccessful Problem Solvers inconsistent problems with those of problem solvers who do. Journal of Educational Psychology, $87(1), 18-32$.

Hong, J., \& Kim, M. (2016). Mathematical abstraction in the solving of ill-structured problems by elementary school students in Korea. Eurasia Journal of Mathematics, Science and Technology Education, 12(2), 267-281. https://doi.org/10.12973/eurasia.2016.1204a

Hong, N. S. (1998). The Relationship Between Well-Structured and Ill-Structured Problem Solving in Multimedia Simulation. The Pennsylvania State University.

Hwang, W., Chen, N., Dung, J.-J., \& Yang, Y.-L. (2007). Multiple Representation Skills and Creativity Effects on Mathematical Problem Solving using a Multimedia Whiteboard System Jian-Jie Dung Yi-Lun Yang. Educational Technology \& Society, 10(2), 191212.

Jonassen, D. (2003). Using cognitive tools to represent problems. Journal of Research on Technology in Education, 35(3), 362-381. https://doi.org/10.1080/15391523.2003.10782391

Jonassen, D. H. (1997). Instructional Design Models for Well-Structured and Ill-Structured Problem-Solving Learning Outcomes. Educational Technology Research and Development, 45(1), 65-94. Retrieved from http://www.jstor.org/stable/30220169

Karaahmetoğlu, K., \& Korkmaz, Ö. (2019). The Effect of Project-based Arduino Educational Robot Applications on Students' Computational Thinking Skills and Their Perception of Basic Stem Skill Levels. Participatory Educational Research (PER), 6(2), 1-14. Retrieved from https://dergipark.org.tr/en/download/article-file/772664

Korkmaz, Ö., \& Bai, X. (2019). Adapting Computational Thinking Scale (CTS) for Chinese High School Students and Their Thinking Scale Skills Level. Participatory Educational Research, 6(1), 10-26. https://doi.org/10.17275/per.19.2.6.1

Lesh, R., Post, T., \& Behr, M. (1987). Representations and Translations among Representations in Mathematics Learning and Problem Solving. In Problems of Representation in the Teaching and Learning of Mathematics of Mathematics (pp. 33-40). Hillsdale NJ: Erlbaum.

Miles, M. B., Huberman, A., \& Saldana, J. (2014). Qualitative Data Analysis. (H. Salmon, Ed.) (Third Edit). California: SAGE Publications, Inc.

Murtafiah, W., Sa'dijah, C., Candra, T. D., Susiswo, \& As'ari, A. R. (2018). Exploring the explanation of pre-service teacher in mathematics teaching practice. Journal on Mathematics Education, 9(2), 259-270. https://doi.org/10.22342/jme.9.2.5388.259-270 
NCTM. (2000). Principles and Standards for School Mathematics. United States of America: The National Council of Teachers of Mathematics Inc. Retrieved from www.nctm.org Niederhauser, D., Ogilvie, C., \& Toy, S. (2013). Solving Ill-structured Problems: Student Behaviour in an Online Problem-solving Environment. In $X$ World Conference on Computers in Education (pp. 38-44). Retrieved from http://edu.rsei.umk.pl/wcce2013/publications/v1/V1.5_127-Niederhauser-fullRFPR.pdf

Özsoy, G., Kuruyer, H. G., \& Çakiroglu, A. (2015). Evaluation of Students ’ Mathematical Problem Solving Skills in Relation to Their Reading Levels. International Electronic Journal of Elementary Education, 8(1), 113-132. Retrieved from www.jejee.com

Pape, S. J. (2004). Middle School Children's Problem-Solving Behavior: A Cognitive Analysis from a Reading Comprehension Perspective. Journal for Research in Mathematics Education, 35(3), 187-219.

Santia, I., Purwanto, Sutawidjadja, A., Sudirman, \& Subanji. (2019). Exploring mathematical representations in solving ill-structured problems: The case of quadratic function. Journal on Mathematics Education, 10(3), 365-378. https://doi.org/10.22342/jme.10.3.7600.365-378

Shin, N., Jonassen, D. H., \& McGee, S. (2003). Predictors of well-structured and ill-structured problem solving in an astronomy simulation. Journal of Research in Science Teaching, 40(1), 6-33. https://doi.org/10.1002/tea.10058

Stoltz, P. G. (2000). Adversity Quotient at Work: Make Everyday Challenges the Key to Your Success-Putting the Principles of AQ into Action. Canada: John Willey and Sons Inc. Wiley Publishers.

Stylianou, D. A. (2010). Teachers' Conceptions of Representation in Middle School Mathematics. Journal of Mathematics Teacher Education, 13(4), 325-343. https://doi.org/10.1007/s10857-010-9143-y

Stylianou, D. A., \& Silver, E. A. (2004). The Role of Visual Representations in Advanced Mathematical Problem Solving: An Examination of Expert- Novice Similarities and Differences. Mathematical Thinking and Learning, 6(4), 353-387. Retrieved from http://sci-hub.tw/10.1207/s15327833mtl0604_1\#

Subanji, S., \& Nusantara, T. (2016). Thinking Process of Pseudo Construction in Mathematics $\begin{array}{lllll}\text { Concepts. International Education } & \text { Studies, }\end{array}$ https://doi.org/10.5539/ies.v9n2p17

Supandi, S., Waluya, S. B., Rochmad, R., Suyitno, H., \& Dewi, K. (2018). Think-Talk-Write Model for Improving Students' Abilities in Mathematical Representation. International Journal of Instruction, 11(3), 77-90.

Swastika, G. T., Nusantara, T., Subanji, \& Irawati, S. (2020). Alteration representation in the Process of Translation Graphic to Graphic. Humanities \& Social Sciences Reviews, 8(1), 334-343. https://doi.org/http://doi.org/10/18510/hsr.2020.8144

Ulusoy, F., \& Argun, Z. (2019). Secondary School Students' Representations for Solving Geometric Word Problems in Different Clinical Interviews. International Journal of Education in Mathematics, Science and Technology (IJEMST), 7(1), 73-92. https://doi.org/10.18404/ijemst.328341

Wong, W. K., Hsu, S. C., Wu, S. H., Lee, C. W., \& Hsu, W. L. (2007). LIM-G: Learnerinitiating instruction model based on cognitive knowledge for geometry word problem comprehension. Computers and Education, 48(4), 582-601. https://doi.org/10.1016/j.compedu.2005.03.009

Xin, Y. P., Jitendra, A. K., \& Buchman, A. D. (2005). Effects of Mathematical Word Problem - Solving Instruction on Middle School Students with Learning Problems. The Journal of Special Education, 39(3), 181-192. 